\title{
Genotoxicity of Monosodium Glutamate: A Review on its Causes, Consequences and Prevention
}

\author{
Rabbani Syed Imam* \\ Department of Pharmacology, College of Pharmacy, Qassim University, Buraidah, KINGDOM OF SAUDI ARABIA.
}

\begin{abstract}
Monosodium Glutamate (MSG) is a common food additive used in processed foods to enhance the taste. The data available on Google scholar, NCBI, PUBMED, EMBASE, Wang fang databases, meta-analysis and Web of Science were reviewed to collect the information on the MSG-induced genetic damages, consequences and its mechanism. The retrieved information indicated that long-term consumption of MSG is associated with metabolic diseases, neurological and reproductive organ defects. Studies also suggested that MSG has the ability to induce genotoxicity. The damages on the genes have the tendency to implicate several diseased states in the host, not only in the present generation but also in the progeny. Considering the consequences of genetic damages on the population, this review was done to find the mutagenic potential of MSG, its causes and the preventive strategy for reducing the MSG-mediated genetic defects.
\end{abstract}

Key words: Monosodium glutamate, Food additive, Genotoxicity, Oxidative stress, Antimutagens.

\section{INTRODUCTION}

Monosodium glutamate is probably one of most frequently used additive in the food industry as a taste enhancer. It was in 1908, a scientist by name Ikeda discovered the taste of glutamate found in seaweeds. MSG can be extracted from molasses by fermentation of beet sugar, sugar cane, starch and corn sugar. MSG is commonly referred as 'Ajinomoto / Chinese salt' and is added in chips, jelly, pastry, candy, pizza, noodles and even protein-rich food products like meat, fish, milk and some vegetables. ${ }^{1}$ MSG is known to produce a type of flavour which the Japanese describe as 'umami' or 'savory'. It has been estimated that at an average in an industrialized country, a person consumes about 0.3 to $1.0 \mathrm{gm}$ of MSG per day. ${ }^{2}$ Glutamate is considered to be one of most richly found amino acid in the body and is also richly present in natural food substances that contain proteins. Glutamate is a known excitatory neurotransmitter in central nervous system that acts through iono- tropic (iGluR) and metabotropic (mGluR) glutamate receptors. The glutamate bound to protein has no taste-enhancing effect and its disintegration takes place only in the small intestine. Studies have indicated that glutamate exhibits its action by binding to its specific receptors located in the taste bunds and stomach and innervations takes place through gastric vagus nerve. ${ }^{3}$

The actions of MSG has been commonly referred as 'Chinese Restaurant Syndrome' and are characterized by headache, flushing, sweating, numbness / burning sensation in mouth and throat, nausea and fatigue. Although these symptoms are reported to vary depending on the concentration and duration of exposure but chronic use of MSG has been linked to several pathological conditions. ${ }^{4}$

Long-term consumption of MSG is reported to cause several health complications such as;
Submission Date: 07-08-2019; Revision Date: 28-08-2019; Accepted Date: 16-09-2019

DOI: 10.5530/ijper.53.4s.145 Correspondence: Dr. Syed Imam Rabbani, Department of Pharmacology, College of Pharmacy, Qassim University Main campus, Buraidah-51452, KINGDOM OF SAUDI ARABIA.

Phone: +966 553899404 E-mail: syedrabbani09@ yahoo.com 
- Metabolic diseases - Diabetes, dyslipidemia, obesity. ${ }^{5}$

- Cardiovascular disease - Hypertension, heart ailments. ${ }^{6}$

- Sleep-breathing and respiratory disorder - Apnea, sleep disturbance. ${ }^{7}$

- Neuro-endocrine defects - Depression, anxiety. ${ }^{8}$

- Reproductive system damages - Alterations in the size and shape of reproductive organs, diminished testosterone levels. ${ }^{9,10}$

- Liver diseases - Hepatitis, elevation in the marker enzymes for liver damage. ${ }^{11}$

- Allergic reactions - Dermatitis, itching, rashes, urticaria, cracked skin. ${ }^{12}$

Clinical case studies have also indicated that MSG exposure increased the perception for pain stimulus and complicated the symptoms in both asthmatic and non-asthmatic patients. ${ }^{13,14}$ Apart from these, MSG exposure is reported to induce damages in the nuclear organization of the host cells leading to genotoxicity. ${ }^{15-17}$ Genetic damages on the host cell is reported to have the tendency to produce mutations. The changes on the genetic set-up if not corrected can lead to health ailments, neurological defects, metabolic diseases and cancer. ${ }^{18}$ The studies to determine the genetic potential of the compound assumes its importance since the defects not only occur in the present generation but also can be inherited to the progeny. ${ }^{19}$ Considering the information on MSG, this review was planned to determine the causes, consequences and prevention of MSG-mediated genotoxicity on the host cells.

\section{Genotoxicity testing}

'Genotoxicity' refers to ability of a substance to cause adverse effects to the genetic component of the cell (DNA, RNA). If the genetic make of the cell is permanently altered leading to heritable defects then it is called as mutation. All genotoxins could be mutagenic in nature. There are various causes for mutation such as exposure to environmental pollutants, occupational exposure to chemical mutagens, radiation, certain medication and viral infection. Mutagens induce damage to the nuclear components by multiple pathways such as direct attack on nucleus, indirectly by producing chemical metabolite that has affinity to DNA, by increasing the production of free radicals. ${ }^{20}$ The consequence of genotoxicity is represented in Figure 1.

The genetic damages results into various diseases, some manifested in the present generation (somatic cell damages) and some will be seen in the progeny (germinal cell damages). Cancer, heart diseases, neurological defects are some of the examples of somatic cell mutation while sickle cell anaemia, cystic fibrosis are categorized under germinal cell nuclear defects. ${ }^{21}$ There are several in-vitro and in-vivo tests available to detect the ability of a compound to induce genetic damage. In these assays, the test compound will be exposed at a predetermined dose and duration by a suitable route of administration to the isolated cells or the whole animals and damages induced to the nuclear component will be measured. Some of commonly employed test methods are as follows; $; 2$

In-vitro methods

- Ames test

- Mouse lymphoma TK assay

- Chromosomal aberrations test

In-vivo methods

- Bone marrow micronucleus test

- Comet assay

- Transgenic assay

\section{In-vitro mutagenic studies for MSG}

An in-vitro test on the mitotic index and genotoxicity of MSG was tested in Vicia faba seedlings and the data showed that MSG dose at $10 \mathrm{~g} / \mathrm{L}$ inhibited the cell division and caused a reduction in mitotic index and additionally produced an increase in the genomic template stability tested by using RAPD-PCR. The analysis indicated that MSG has significant genotoxic potential and also reduce the seed germination property in $V . f a b a .^{23}$

In this study, Allium cepa assay was used to evaluate the genotoxic and cytotoxic potential of MSG. The root tips of onion were exposed to four concentrations of MSG (1, 3, 5 and $7 \mathrm{~g} / \mathrm{L})$ dissolved in distilled water. Macroscopic (morphology and colour of roots) and microscopic (mitotic index and chromosomal aberrations) examinations were done on the root tips. The analysis of the results indicated that the tested doses of MSG reduced the growth of roots and changed the color of root tips from normal pink color to brownish / black colour. MSG also induced chromosomal aberration at telophase and reduced (non-significantly) the mitotic index..$^{24}$

In a similar study, MSG tested on Allium cepa produced significant chromosome aberrations like bridges, fragments, disturbance, sticky chromosomes and other morphological abnormalities like enlargement of cells in root tips. ${ }^{25}$ One more research on onion root tip indicated a reduction in mitotic index besides chromosomal damage with MSG. ${ }^{22}$ Also in another findings, the data on the study in onion root tip suggested both chromosomal damage and reduced mitotic index. ${ }^{26}$ The results 
suggested that MSG has the potential to induce both genotoxicity as well as cytotoxicity in Allium cep $a^{24-26}$

The genotoxic potential of MSG was evaluated by chromosome aberrations (CAs), sister-chromatid exchanges (SCEs), cytokinesis-blocked micronucleus (CBMN) and random amplified polymorphic DNA-polymerase chain reaction (RAPD-PCR) in cultured human lymphocytes and alkaline comet assays in isolated human lymphocytes. The studies were done using six concentrations of MSG viz., 250, 500, 1000, 2000, 4000 and $8000 \mu \mathrm{g} /$ $\mathrm{mL}$. The observation of the study indicated that MSG significantly and in a dose-dependent manner increased the frequencies of CAs, SCEs and MN. The RAPDPCR test suggested both increase and decrease in band intensity and gain or loss of bands and the comet assay revealed significant DNA damage. The results indicated that MSG might possess the genotoxic potential in the isolated human peripheral lymphocytes. ${ }^{27}$

\section{In-vivo mutagenic studies for MSG}

The study on the Drosophila melanogaster indicated that MSG exposure produced changes in the wing development due to the action of MSG on the integrity of chromosome and transcription of genes. The results suggest that MSG can produce new mutation which is recessive in its action and has the potential to alter phenotype in Drosophila. ${ }^{28}$

The genotoxic effect of MSG was tested at $4 \mathrm{mg} / \mathrm{g}$ body weight using the rat bone marrow micronucleus test. The data indicated that administration of MSG significantly increased the formation of micronucleated polychromatic erythrocytes besides increasing the oxidative stress compared to the control groups. This study was done to evaluate the influence of dietary antioxidant such as vitamin $\mathrm{C}$, vitamin $\mathrm{E}$ and quercetin in the MSG-induced oxidative damage to organs such as liver, kidney and brain in rats. The results suggested that antioxidant potential of a compound can reduce the number of micron cleated erythrocytes and toxic manifestations on organs. ${ }^{29}$

The ability of MSG to induce genotoxicity in palatal mucosa was studied in adult albino rats. MSG was tested at 20 and $40 \mathrm{mg} / \mathrm{kg}$ for two months and then palatal samples were isolated. The samples were stained with haematoxylin and eosin stains and the histological examination revealed papillary fold projections, bulbous shape rete pegs (epithelial cell projections in connective tissues) in the basal cell layer of oral epithelium. The molecular study indicated reduction in DNA quality and quantity in these cells compared to the control group. The study concludes that MSG has genotoxic effects on the palatal mucosa of rats. ${ }^{30}$
A study done to evaluate the protective effect of Moringa leaf extract against the MSG induced cellular and nuclear damages in rats indicated that administration of MSG (5 mg/ $\mathrm{kg}$ ) produced significant DNA damage besides increasing the PCNA and p53 expressions compared to the untreated group. These effects were related to the oxidative potential of MSG where it not only produced organ level damage but also induced significant genotoxicity. The observation suggests that Moringa leaf extract due to its antioxidant property has the potential to reduce the nuclear-defect complications of MSG ${ }^{15}$

The study conducted to find the influence of MSG on the markers of genotoxicity indicated that when adult male Sprague dawley rats were treated with MSG, a significant increase in expression of gadd45b (Growth Arrest and DNA Damage Inducible Beta) marker was observed. The treatment also dose-dependently increased the IL-8 and $\mathrm{Bax}$ and reduced the $\mathrm{Bcl}-2$ levels. An increase in the biomarkers for the liver damage was also observed. The authors concluded that MSG-induced genotoxicity could be mediated through expression of gadd $45 \mathrm{~b}$ gene that has an influence on the cell growth and death program signalling mechanism and MSG-mediated liver toxicity has tendency to show more complications in patient with pre-existing hepatic diseases. ${ }^{16}$

A study to evaluate the modulatory effect of Chlorella vulgaris and Spirulina platensis against the MSG induced genotoxicity and apoptosis indicated that MSG increased DNA fragmentation and apoptosis. The finding showed that MSG up regulated the mRNA Bax, caspase- 3 genes, down-regulating Bcl-2 gene expression besides inducing significant oxidative stress and hepatic cell damage. ${ }^{17}$

\section{Mechanism suggested for MSG-induced genotoxicity}

The mechanism reported for MSG-induced genotoxicity is both direct as well as indirect attack on the nucleus. In the direct attack, the data from the earlier studies indicated that MSG induced significant chromosomal aberrations, clumping and stickiness of chromosomes in the anaphase. The stickiness of chromosomes can occur due to disturbances in protein adhesion or DNA / RNA metabolism. The study also indicated that MSG can inhibit the spindle fibre and can influence the separation of anaphase. ${ }^{31}$

The nuclear fragments observed in in-vivo micronucleus and comet test also suggests the direct nuclear damages. Micronucleus is the left-over part of main nucleus in the cytoplasm after the nuclear injury. During erythropoiesis, the main nucleus will get expelled out; however the damage part will remain as micronuclei. ${ }^{29}$ The comet 
assay indicates the extent of damage to the nuclear part of the cell has undergone. If there is a large fraction is left behind as an extended tail, it is an indicative of severity of DNA damage. The observation from MSG study indicated an increase in the DNA tail length (TL), DNA tail intensity (TI) and DNA tail moment (TM). ${ }^{16}$ MSG also reported to increase the DNA breaking number, making the super-coiled loops of DNA to relax more and cause large fraction of DNA to move. ${ }^{32}$ These studies suggested the ability of MSG to induce nuclear damage in the host cells.

In the indirect mechanism, MSG is found to enhance the oxidative stress as well deplete the antioxidant defence enzymes such as superoxide dismutase, catalase and glutathione peroxidase in the host. ${ }^{33}$ The markers of oxidative stress were indicated by the elevation in the level of malondialdehyde (MDA) and Xanthine Oxidase (XO). Lipid peroxidation in cell membrane induces structural changes in the polyunsaturated fatty acids which are essential for normal functioning of the cells. MDA is considered to be final end-product of lipid peroxidation of ROS. ${ }^{34}$

On the other hand, XO catalyses the conversion of hypoxanthine to xanthine and then to uric acid. In normal condition it does not contribute in free radical generation. However, in pathological states, XO can catalyse the reduction of oxygen to form superoxide anions and hydrogen peroxide contributing in oxidative stress..$^{35} \mathrm{It}$ is reported that due to alteration in oxidative-antioxidant balance, the accumulated ROS will now start attacking the host cellular components such as DNA, lipids and proteins leading to alterations in the biological functions, mutations and apoptosis. ${ }^{36,37}$

Oxidative stress due to reactive oxygen species is known to cause apoptosis. The programmed cell death / apoptosis is the normal physiological response shown by most multi-cellular organism. The response occurs to ageing, cell injury and can be triggered by several factors such as oxidative stress. It was reported earlier that MSG administration induces apoptosis by causing the down-regulation of $\mathrm{Bcl}-2$ protein in thymus glands. ${ }^{38}$ According to Rezzani et al. (2003) the glutamate induced apoptosis can be related to the activation of mGluR5 receptors leading to increased intracellular $\mathrm{Ca}^{2+}$. The abnormally increased $\mathrm{Ca}^{2+}$ results in excessive uptake of $\mathrm{Ca}^{2+}$ into the mitochondria which then starts the cell death mechanisms by releasing the pro-apoptotic factors in the cytosol such as procaspase, cytochrome C, apoptosis-inducing factor, apoptosis protease-activating factor 1 and, ultimately activates caspases to execute the cellular death. Calcium-mediated activation also reported to cause the generation of free radicals such as superoxide anions. ${ }^{39}$

Studies also indicated that MSG treatment significantly down-regulated and up-regulated the Bcl-2 and Bax proteins level in the liver homogenate, respectively. $\mathrm{Bcl}-2$ are referred as anti-apoptotic proteins and its proapoptotic partner is $\mathrm{Bax}$. The family of $\mathrm{Bcl}-2$ proteins are confined to a small area on the cytoplasmic face of the mitochondrial outer membrane, endoplasmic reticulum and nuclear envelope, maintains the mitochondrial membrane integrity by preventing the release of cytochrome $\mathrm{c}$ which, together with APAF-1, facilitates the activation of caspase- $9 .{ }^{40}$

In comparison, the pro-apoptotic Bax, identified as an inhibitory binding partner of $\mathrm{Bcl}-2$, is activated in response to genotoxic stress, causing conformational changes, membrane-insertion and oligomerization to shape a channel in the mitochondrial outer membrane, through which cytochrome $\mathrm{C}$ exits to the cytosol to trigger caspase-9, initiating the caspase cascade activation and hence cell death (Figure 2). Further, the homodimer formation ability of $\mathrm{Bax}$ is considered as the dominant regulator of the cell death signal. The Bax/Bax homodi-

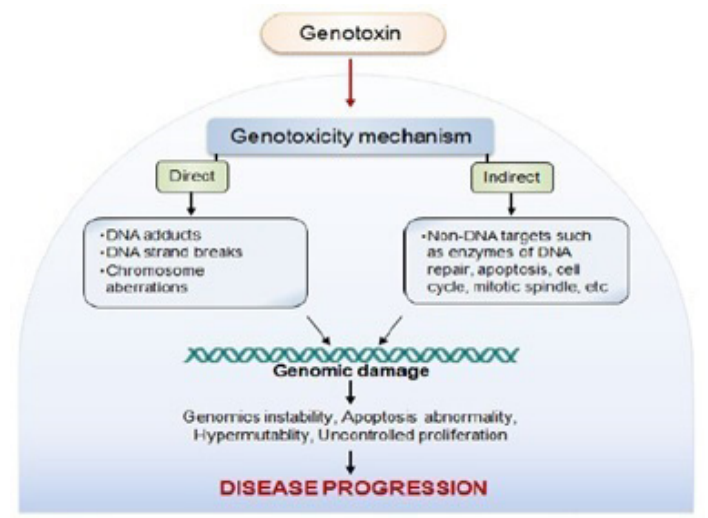

Figure 1: Schematic representation of genotoxicity and its progression to disease condition. ${ }^{20}$

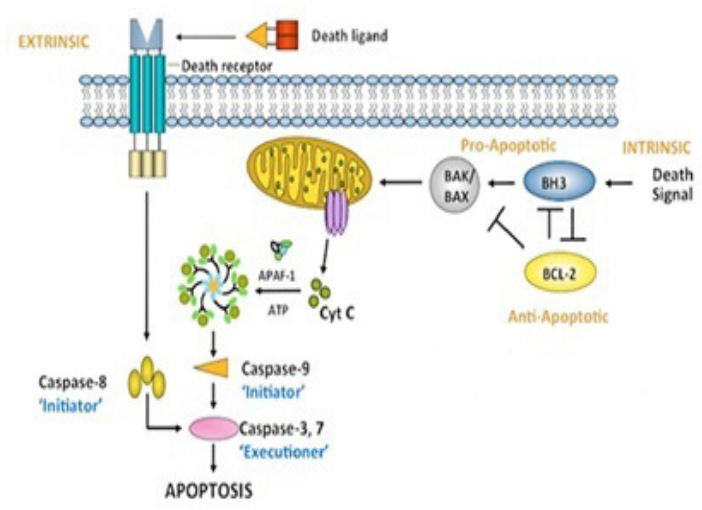

Figure 2: Schematic representation to indicate the molecular mechanism of apoptosis. ${ }^{40-42}$ 
mer formation can antagonize the anti-apoptotic function of the $\mathrm{Bcl}-2$ protein, leading to cytochrome $\mathrm{C}$ liberation and apoptosis initiation. ${ }^{41}$

MSG has been reported to elicits the response of stress genes called gadd45 (growth arrest and DNA damage inducible 45). The genes are concerned in cell cycle arrest, DNA repair and apoptosis. The expression of the gene is inducible due to different types of stress including oxidative and genotoxic. ${ }^{42}$ In addition to this, MSG has been reported to the trigger several proinflammatory mediators such as interleukin-8, nuclear transcription factor-kappa $\mathrm{B}(\mathrm{NF}-\mathrm{kB})$, Tumor necrosis factor $(\mathrm{TNF}-\alpha){ }^{31,43}$

Gadd45b is considered to be a pro-apoptotic and growtharresting protein and executes these actions depending on the nature and strength of the stress. In mammalian cells, the response of this gene is considered to maintain the cellular genomic integrity by averting the fixation of permanent damage from genotoxic stress. The function of the gene involves activation of cell cycle arrest at G1/S and G2/M transitions and activation of the cell death program depending on the extent of damage. The study suggests that MSG exposure triggered apoptosis rather than DNA repair. ${ }^{40}$ Enhanced apoptosis is also considered as a marker of genotoxicity. ${ }^{43,44}$

Studies also indicated that MSG exposure increases the expression of PCNA and p53 in rats. These are the biomarkers reported for the cell proliferation and apoptosis. ${ }^{45}$ Studies further suggested that MSG has the potential to suppress the tumor suppressive genes. ${ }^{46}$

Based on these information, the genotoxic mechanism of MSG can be summarized as;

- Direct attack on the nuclear components of the cells.

- Enhancing the oxidative stress by increasing the production of ROS and reducing the antioxidant enzymes.

- ROS mediated cellular damage leading to apoptosis and mutations.

- Inhibition in the action of tumor suppressive genes.

- Triggering the release of mediators for inflammation and cell proliferation.

\section{MSG and carcinogenicity}

Studies conducted in the past reported that MSG administration is associated with carcinogenesis. In one such study, it was observed that MSG-induced obesity caused steatosis and steatohepatitis, resembling the preneoplastic lesions that were commonly seen in human non-alcoholic fatty liver disease. The cellular hyperexcitability involving the sodium gated-voltage channels and ligand excitatory glutamate as well the increased oxidative stress are reported to be important risk-factors for these pre-neoplastic lesions. ${ }^{47}$

In another study, new born mice treated with MSG (2 $\mathrm{mg} / \mathrm{g}$, s.c., for 4 days) produced several obesity-related parameters such as hyperinsulinemia, hypercholesteremia and hyperglycemia. The study further indicated that animals tested with MSG had shown more tendencies to develop the colorectal cancer. ${ }^{48}$ The findings suggested that metabolic programming of several types of cancer cells got altered after MSG exposure. Glutamine present in the body plays an important role in getting converted to glutamate by glutaminase tumours and is involved in the synthesis of ATP. This process reported to regulate the energy consumption in the cancer cells. ${ }^{49}$ Studies have indicated that obesity being a major complication of MSG has the tendency to amplify the incidences of carcinogenicity. In addition to the mechanism discussed already, the pathways also include the activation of insulin-IR-ERK1/2 and modulation of antiapoptotic action of immune cells. ${ }^{50}$ However, some researchers have indicated that these conditions do not normally mimic in human and have little relevance for human tumorigenesis. ${ }^{51}$

\section{Strategies for preventing the MSG-mediated genotoxicity}

Since it is inevitable to avoid the exposure to food additives such as MSG, the best way to minimize their effects is by increasing the use of substances that possess ant mutagenic potential. There are several examples of substances (both synthetic and natural) reported in literature where the compounds exhibited ant mutagenic property.

Their mechanisms of ant mutagenesis include, ${ }^{51,53}$

- Direct inactivation of mutagen

- Increasing the antioxidant status

- Inhibiting the conversion to active mutagens

- Increasing the level of metabolizing enzymes

- Rapid elimination from host system.

The compounds that are reported to possess the ant mutagenic property against the MSG are Origanum majorana, Ruta chalepensis, Vicia faba, Moringa oleifera, Cblorella vulgaris and Spirulina platensis. And the most common mechanism reported for the ant mutagenesis is the antioxidant effect of the natural substance. . $5,16,23$

From the data discussed, it can be noted that generation of ROS plays an important role in the mutagenesis; their prevention is reported to be an important strategy for the ant mutagenesis. The compounds that exhibited antioxidant activity has been reported to 
reduce the interaction of ROS with targets in the DNA, increased the level of protective enzymes such as SOD, CAT, GSH-Px, augmented the DNA repair / synthesis mechanism. ${ }^{54}$

\section{CONCLUSION}

Monosodium glutamate extensively used in food industry has been tested for genotoxic potential in the in-vitro and in-vivo tests. The data from this review suggested that MSG has the potential to induce the nuclear damages in the host cells. The available information indicated that MSG could produce genetic damages both by direct as well as indirect mechanisms. In the direct action, MSG can induce chromosomal aberrations, clumping and stickiness of chromosomes, besides inhibiting the spindle fibre in the anaphase. The indirect effect of MSG is mediated through the generation of oxidative stress in the host cells. The reactive free radicals have the ability to cause direct effect on the nuclear component of cells besides, inducing structural and functional defects in the genes. Molecular mechanisms such as alterations of Bcl2, Bax protein, gadd45, NF-kB, TNF- $\alpha$ and p53 levels have also been linked to the genotoxic effects of MSG. Alterations in the genes if not corrected can leads to several diseased states not only in the present generation but also in the offspring.

Enhancing the host defence mechanisms is one of the most effective strategy to counteract against the deleterious effects of environmental mutagens and carcinogens that accidently or intentionally enter our host system. Increasing the use of natural ant mutagens in the diet has the tendency to increase the host anti-mutagenic mechanisms that will effectually provide protection against genotoxic complications of substances that are difficult to avoid in our daily life.

\section{ACKNOWLEDGEMENT}

None.

\section{CONFLICT OF INTEREST}

The authors declare that there are no conflicts of interest.

\section{ABBREVIATIONS}

MSG: Monosodium glutamate; iGluR: Inotropic glutamate receptors; mGluR: Metabotropic glutamate receptors; RAPD-PCR: Random amplified polymorphic DNA-polymerase chain reaction; CAs: Chromosome aberrations; CBMN: Cytokines blocked micronucleus;
SCEs: Sister Chromatid exchanges; MN: Micronucleus; PCNA: Proliferating cell nucleus antigen; ILs: Interleukins; Bcl-2: B cell lymphoma-2; Bax: Bcl-2 associated $\mathrm{X}$ protein; TL: Tail length (DNA); TI: Tail intensity (DNA); TM: Tail moment (DNA); XO: Xanthine oxidase; MDA: Malondialdehyde; ROS: Reactive oxygen species; NF-kB: Nuclear transcription factor kappa-B; TNF: Tumor necrosis factor; SOD: Superoxide dismutase; CAT: Catalase; GSH-Px: Glutathione peroxidise.

\section{REFERENCES}

1. Ikeda K. New Seasonings. Chem Senses. 2002;27(9):847-9.

2. Geha RS, Beiser A, Ren C, Patterson R, Greenberger PA, Grammer LC, et al. Review of Alleged Reaction to Monosodium Glutamate and Outcome of a Multicenter Double-Blind Placebo-Controlled Study. Journal of Nutrition. 2000;130(4S Suppl):1058S-62S.

3. Nelson G, Chandrashekar J, Hoon MA, Feng L, Zhao G. An amino-acid taste receptor. Nature. 2002;416(6877):199-202.

4. Schaumburg $\mathrm{HH}$, Byck R, Gerstl R, Mashman JH. Monosodium L-glutamate: Its pharmacology and role in the Chinese restaurant syndrome. Sci. 1969;163(3869):826-8.

5. Olney JW. Brain lesions, obesity and other disturbances in mice treated with monosodium glutamate. Science. 1969;164(3880):719-21.

6. Shi Z, Yuan B, Taylor AW, Dai Y, Pan X. Monosodium glutamate is related to a higher increase in blood pressure over 5 years: Findings from the Jiangsu Nutrition Study of Chinese adults. Journal of Hypertension. 2011;29(5):846-53.

7. Shi Z, Wittert GA, Yuan B, Dai Y, Gill TK. Association between monosodium glutamate intake and sleep-disordered breathing among Chinese adults with normal body weight. Nutrition. 2013;29(3):508-13.

8. Pelaez B, Blazquez JL, Pastor FE, Sanchez A, Amat P. Lectinhistochemistry and Ultrastructure of Microglial Response to Monosodium GlutamateMediated Neurotoxicity in the Arcuate Nucleus. Histology and histopathology. 1999;14(1):165-74.

9. Eweka AO, Eweka A. Om'iniabohs FAE. Histological Studies of the Effects of Monosodium Glutamate of the Fallopian Tubes of Adult Female Wistar Rats. North American Journal of Medical Sciences. 2010;2(3):146-9.

10. Miskowiak B, Limanowski A, Partyka M. Effect of Perinatal Administration of Monosodium Glutamate (MSG) on the Reproductive System of the Male Rat. Endokrynologia Polska. 1993;44(4):497-505.

11. Eweka AO, Igbigbi PS, Ucheya RE. Histochemical Studies of the Effects of Monosodium Glutamate on the Liver of Adult Wistar Rats. Annal of Medical and Health Sciences Research. 2011;1(1):21-9.

12. Yang $\mathbf{W H}$, Drouin MA, Herbert M, Mao $\mathrm{Y}$, Karsh J. The Monosodium Glutamate Symptom Complex: Assessment in a Double-Blind, PlaceboControlled, Randomized Study. Journal of Allergy and Clinical Immunology. 1997;99(6):757-62.

13. Shimada A, Castrillon EE, Baad-Hansen L, Ghafouri B, Gerdle B, Wåhlén $\mathrm{K}$. Increased pain and muscle glutamate concentration after single ingestion of monosodium glutamate by myofascial temporomandibular disorders patients. European Journal of Pain. 2016;20(9):1502-12.

14. Stevenson DD. Monosodium glutamate and asthma. Journal of Nutrition. 2000;130(4): 1067S-73S.

15. Albrahim T, Binobead MA. Roles of Moringa oleifera Leaf Extract in Improving the Impact of High Dietary Intake of Monosodium Glutamate-Induced Liver Toxicity, Oxidative Stress, Genotoxicity, DNA Damage and PCNA Alterations in Male Rats. Oxidative Medicine and Cellular Longevity. 2018. Hamdy GM, Saleh EM, Seoudi DM. Does Monosodium Glutamate Induce Genotoxic Stress Through Altering Gadd45b Gene Expression?. Research Journal of Pharmaceutical, Biological and Chemical Sciences. 2018;9(3):1058-71.

16. El-makawy Al, Abdel-Aziem SH, Ibrahim FM, Sharaf HA, Abd-Elmoneim OA, Darwish AM. Potential modulator role of Chlorella vulgaris and Spirulina 
platensis on monosodium glutamate oxidative stress, genotoxicity, apoptotic gene expression and histopathological alterations. International Journal of Pharmaceutical Technology and Research. 2016;9 (11):161-77.

17. Umbuzeiro GA, Heringa M, Zeiger E. In vitro Genotoxicity Testing: Significance and Use in Environmental Monitoring. Advances in Biochemical Engineering and Biotechnology. 2017;157:59-80.

18. Eastmond DA, Hartwig A, Anderson D, Anwar WA, Cimino MC. Mutagenicity testing for chemical risk assessment: Update of the WHO/IPCS Harmonized Scheme. Mutagenesis. 2009;24(4):341-9.

19. Srivastava R, Mishra N, Singh UM, Srivastava R. Genotoxicity: Mechanisms and its impact on human diseases. Octa Journal of Biosciences. 2016;4(2):6770 .

20. Martincorena I, Campbell PJ. Somatic mutation in cancer and normal cells. Science. 2015;349(6255):1483-9.

21. Cimino MC. Comparative overview of current international strategies and guidelines for genetic toxicology testing for regulatory purposes. Environmental and Molecular Mutagens. 2006;47(5):362-90.

22. Zedan AMG, Galal OA, Al-Anany FS. Potential effect of some natural food additives against monosodium glutamate-induced genotoxicity in Vicia faba. Egyptian Journal of General Cytology. 2017;46:371-88.

23. Adeyemo OA, Farinmade AE. Genotoxic and cytotoxic effects of food flavor enhancer, monosodium glutamate (MSG) using Allium cepa assay. African Journal of Biotechnology. 2013;12(13):1459-66.

24. Khatab HA, Elhaddad NS. Evaluation of Mutagenic Effects of Monosodium Glutamate Using Allium cepa and Antimutagenic Action of Origanum majorana L. and Ruta chalepensis Medical Plants. British Biotechnology Journal. 2015;8(1):1-11.

25. Turkoglu S. Evaluation of genotoxic effects of five flavour enhancers (glutamates) on the root meristem cells of Allium cepa. Toxicology and Industrial Health. 2015;31(9):792801.

26. Ataseven N, Yüzbaşıŏlu D, Keskin AÇ, Ünal F. Genotoxicity of monosodium glutamate. Food Chemical Toxicology. 2016;91:8-18.

27. Sarfaraz S, Kumar J. Effects of Monosodium Glutamate on Drosophila melanogaster. LAP LAMBERT Academic Publishing, Brivibas gatve Germany. 2014.

28. Farombi EO, Onyema OO. Monosodium glutamate-induced oxidative damage and genotoxicity in the rat: Modulatory role of Vitamin C, Vitamin $\mathrm{E}$ and quercetin. Human Experimental Toxicology. 2006;25(5):251-9.

29. Mohammed SS. Monosodium glutamate-induced genotoxicity in rat palatal mucosa. Tanta Dentistry Journal. 2017;14(3):112-9.

30. Onyema OO, Farombi EO, Emerole GO, Ukoha AI, Onyeze GO. Effect of Vitamin $\mathrm{E}$ on monosodium glutamate induced hepatotoxicity and oxidative stress in rats. Indian Journal of Biochemistry and Biophysics. 2006;43:20-4.

31. Cedervall B, Wong R, Albright N, Dynlacht J, Lambin P, Dewey WC Methods for the quantification of DNA double-strand breaks determined from the distribution of DNA fragment sizes measured by pulsed-field gel electrophoresis. Radiation Research. 1995; 143(1):8-16.

32. Singh K, Ahluwalia P. Studies on the effects of monosodium glutamate (MSG) administration on some antioxidant enzymes in the arterial tissue of adult male mice. Journal of Nutrition Sciences and Vitaminology. 2003;49(2):145-8.

33. Gutterridge JC. Lipid peroxidation and antioxidants as biomarkers of tissue damage. Clinical Chemistry. 1995;41(12):1819-28.

34. Jaeschke H. Xanthine oxidase-induced oxidant stress during hepatic ischemia-reperfusion: Are we coming full circle after 20 years?. Hepatology. 2002;36(3):761-3.
35. Castro L, Freeman BA. Reactive oxygen species in human health and disease. Nutrition. 2001;2(17):161-5.

36. Bonnefont-Rousselot D, Bastard JP, Jaudon MC. Consequences of the diabetic status on the oxidant/antioxidant balance. Diabetes and Metabolism. 2000;26(3):163-76.

37. Pavlovic V, Cekic S, Sokolovic D. Modulatory effect of monosodium glutamate on rat thymocyte proliferation and apoptosis. Bratislavske Lekarske Listy. 2006;107(5):185-91.

38. Rezzani R, Corsetti G, Rodella L. Cyclosporine-A treatment inhibits the expression of metabotropic glutamate receptors in rat thymus. Acta Histochemica. 2003;105(1):81-7.

39. Burlacu A. Regulation of apoptosis by Bcl-2 family proteins. Journal of Cellular and Molecular Medicine. 2007;7(3):249-57.

40. Oltvai $\mathrm{ZN}$. Bcl-2 heterodimerizes in vivo with a conserved homolog, Bax, that accelerates programmed cell death. Cell. 1993;74(4):609-19.

41. Moskalev AA, Smit-McBride Z, Shaposhnikov MV, Plyusnina EN, Zhavoronkov A, Budovsky A, et al. Gadd45 proteins: Relevance to aging, longevity and age-related pathogenesis. Ageing Research Reviews. 2012;11(1):51-66.

42. Banerjee R, Karpen S, Siekevitz M, Lengyel G, Bauer J, Acs G. Tumor necrosis factor-alpha induces a kappa B sequence-specific DNA-binding protein in human he- patoblastoma HepG2 cells. Hepatology. 1989;10(6):1008-13.

43. Vairapandi M, Balliet AG, Hoffman B, Liebermann DA: Gadd45b and Gadd45g are cdc2/cyclinB1 kinase inhibitors with a role in $S$ and G2/M cell cycle checkpoints induced by genotoxic stress. Journal of Cell Physiology. 2002;192(3):327-38.

44. Eweka AO, Om'Iniabohs F. Histological studies of the effects of monosodium glutamate on the liver of adult Wistar rats. The Internet Journal of Gastroenterology 2008; 6: 1-8.

45. Eweka AO, Eweka A, Om'Iniabohs FAE. Histological studies of the effects of monosodium glutamate on the fallopian tube of adult female Wistar rats. North Americal Journal of Medical Science. 2010;2(3):146-49.

46. Nakanishi Y, Tsuneyama K, Fujimoto M, Salunga TL, Nomoto K, An JL, et al. Monosodium glutamate (MSG): A villain and promoter of liver inflammation and dysplasia. J of Autoimmunity. 2008;30(1-2):42-50.

47. Hoang BX, Levine SA, Pham P, Shaw DG. Hypothesis of the cause and development of neoplasms. European Journal of Cancer Previews. 2007; 16(1):55-61.

48. Scalise M, Pochini L, Galluccio M, Console L, Indiveri C. Glutamine transport and mitochondrial metabolism in cancer cell growth. Frontiers in Oncology. 2017;7:306-10.

49. Freeman M. Reconsidering the effects of monosodium glutamate: A literature review. Journal of American Academy of Nurse Practitioners. 2006;18(10):482-6.

50. Fujimoto M, Tsuneyama K, Nakanishi Y, Salunga TL, Nomoto K, Sasaki Y, et al. A dietary restriction influences the progression but not the initiation of MSG-Induced non-alcoholic steatohepatitis. Journal of Medicinal Food. 2014;17(3):374-83.

51. DeFlora S. Mechanisms of inhibitors of mutagenesis and carcinogenesis. Mutation Resrearch. 1998;402(1-2):151-8.

52. Kada T, Inoue T, Ohta T, Shirasu Y. Antimutagens and their modes of action. In: Hollaende, (Eds.). Life Sciences, Plenum, New York. 1985;39:181-96.

53. Lee KW, Bode AM, Dong Z. Molecular targets of phytochemicals for cancer prevention. National Reviews on Cancer. 2011;11(3):21118.

Cite this article: Rabbani SI. Genotoxicity of Monosodium Glutamate: A Review on its Causes, Consequences and Prevention. Indian J of Pharmaceutical Education and Research. 2019;53(4s):s510-s517. 


\section{PICTORIAL ABSTRACT}

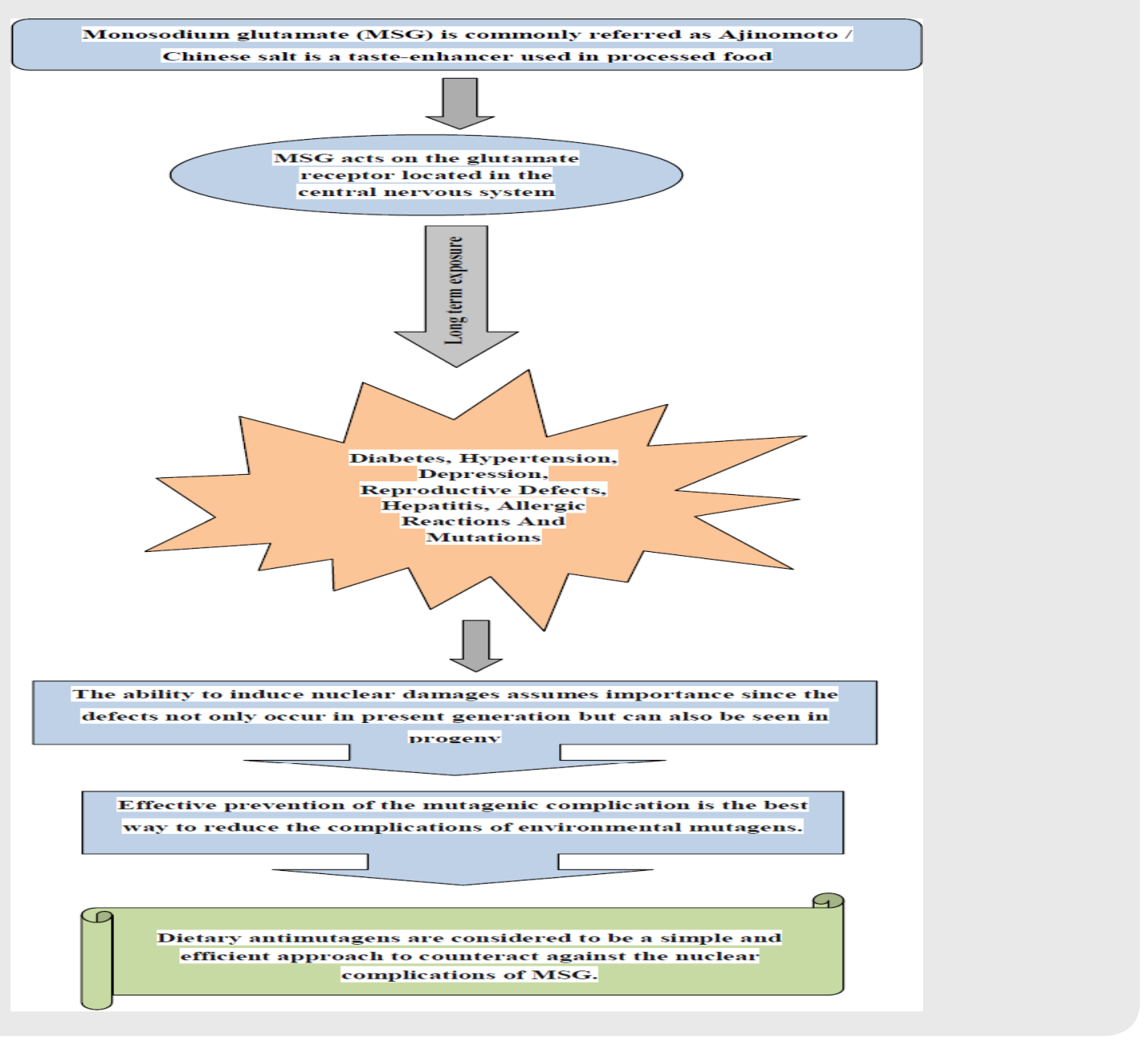

